\title{
Exploring Teaching Training Using Metaphors among Arab Students in Israel
}

\author{
Khawla Zoabi, Yaser Awad \\ The College of Sakhnin of Teacher Education, Sakhnin, Israel \\ Email: Khawla_zoabi2011@hotmail.com, Awad_y@netvision.net.il
}

Received March $2^{\text {nd }}, 2012$; revised April $6^{\text {th }}$, 2012; accepted April $15^{\text {th }}, 2012$

\begin{abstract}
Many studies reveal that personal insights and growth can be followed through the study of narratives and metaphors in the field of education. Yet, there is a striking lack of studies in education that analyzes students' metaphors regarding teacher-training practicum as a continuous process, and there is a lack of such studies in various cultural contexts. This paper describes how Arab teacher-training students described their impressions of their practical experience through personal stories entirely based in metaphoric language. The study was carried out in a multiple case study format, in which the cases are the stories of the students. The stories were written in Arabic the mother tongue of the students. This paper contributed to the body of knowledge available about student teachers' practical experiences in two ways: first, by providing a detailed understanding of how students perceive their practicum; and second, since knowledge through metaphors can provide direction in structuring training courses for student teaching in accordance with student insights and by addressing their needs, such an understanding will be useful to teachers and instructors and can guide them in providing training that is relevant, rational, and supportive.
\end{abstract}

Keywords: Component; Formatting; Style; Styling; Insert

\section{Introduction}

The main objective of teacher training is to prepare students to function in a professional manner as teachers (Lamm, 1989). Teacher training is based on theoretical courses and a practical experience module. Through a combination of theoretical and practical studies, students are expected to develop practical wisdom, which is a system of practical and simple principles that characterize coping with teaching situations (Evans, 2007). It reflects sensitivity and awareness of the essential in real life situations and develops ways of dealing with them. Practical wisdom is arrived at through theory, which fills the need for order and verification of events that take place during a practicum (Lunenberg \& Korthagen, 2009). The practicum is a significant and decisive factor in the professional socialization process because it concerns what happens in the real world during actual teaching in the school, in a classroom situation, and the internal reality of teachers, which includes their beliefs and their evolving self-identity as professionals (Dayan, 2000; Smith \& Ari, 2005; Reichenberg \& Sagi, 2003; Lunenberg \& Korthagen, 2009). Moreover, the practicum has multiple and various objectives. It aims to expose students to theoretic knowledge in teaching and the connection between practice and theory (Lunenberg \& Korthagen, 2009); and to didactic points of view, developing lesson plans, and various methods and styles of teaching (Khalil \& Asadi, 2005; Beyer, 1990). The practicum provides an opportunity to experience an educational environment and form ties with teaching staff and parents (Silberstein, 2002). In addition, it strives to develop the ability to exercise discretion and acquire professional goal-oriented techniques for activating pedagogical considerations, and to develop feelings of responsibility for inculcating knowledge and building the characters and identities of their pupils (Beyer,
1990, Reichenberg \& Sagi, 2003; Sarel, 1997). It seeks to provide an opportunity for the student to learn through personal experience (Khalil \& Asadi, 2005); and to develop reflective thinking that encourages practical wisdom in the student teacher and helps them become aware of the information they possess (Dickman, 2005). Furthermore, the practicum is designed to help students form their educational philosophies and beliefs; develop their perspectives, orientations, philosophies, and principles; and increase their awareness of the practicum as a developmental process influenced by the personal and cultural characteristics of the trainees, the macro-political context, the structure of the educational curriculum, and the organizational environment in which the practical experience takes place (Awad, Zoabi, \& Khalil, 2009; Parkison, 2008a, 2008b).

Students in teacher-training courses and many of their teachers ascribe much higher importance to practical classroom experience than they do to academic courses (Lzovsky \& Schrift, 1992; Hoy \& Woolfolk, 1990; Shapiro, 1991; Awad et al., 2009). Practical experience usually begins with preparation for field work during coursework and by observation of experienced teachers in schools. The students are expected to put into practice what they have studied in their academic courses, to implement teaching methods, and to be familiar with all facets of the work of a teacher. They are provided with opportunities to create lines of communication with the administration, teachers, and parents (Lzovsky \& Schrift, 1992; Reichenberg, 1998). The practicum provides an opportunity for teachers-in-training to become familiar with the various activities of the teacher and to build ties with the pupils, the teaching staff, the administration, and the parents (Gilad, 2005). The experience is consequently a complex crossroads for students, since it is the point at which theoretic studies meet real educational situations. Likewise, it is where the three axis of the practicum 
meet: the faculty supervisor, the cooperating teacher, and the student (Silberstein, Pnyevesky, \& Goose, 2005). Student teachers must deal on the emotional level with dissonance between their attitudes and beliefs and what actually occurs in the field; and on the cognitive level, with a variety of didactic methods and strategies (Reichenberg, 1998).

Numerous research studies reveal that personal insights and growth can be followed through the study of narratives and metaphors in the field of education (Ville \& Khalt, 2007; White, 2006; Bozik, 2002; Bujold, 2004; Bullough \& Stokes, 1994; Cornelissen, 2004; Fresko, 2009; Lawley \& Tompkins, 2000; Koro-Ljungberg, 2001; Kupferberg \& Gilat, 2002; Zilberman, Danter, \& Cohen, 1995). Some studies in education focus on stories originating from professional experience, including those of students in teacher-training courses (Fresko, 2009; Hale, Snow-Gerono, \& Morales, 2008). Yet, there is a striking lack of studies in education that analyzes students' metaphors regarding teacher-training practicum as a continuous process. In addition, there is a lack of such studies in various cultural contexts. Therefore, this paper aims to describe how Arab teacher-training students described their impressions of their practical experience through personal stories entirely based in metaphoric language. Specifically, this paper strives to learn from the metaphors about the teaching as a rich and complex process.

The study was carried out in a multiple case study format, in which the cases are the stories of the students. The stories were written in the mother tongue of the students, Arabic. Moreover, this paper also aims to contribute to the body of knowledge available about student teachers' practical experiences in two ways: first, by providing a detailed understanding of how students perceive their practicum; and second, since knowledge through metaphors can provide direction in structuring training courses for student teaching in accordance with student insights and by addressing their needs, such an understanding will be useful to teachers and instructors and can guide them in providing training that is relevant, rational, and supportive (Bozik, 2002).

This paper is composed of five sections. The next section presents the theoretical foundations of the practicum and teacher training and the role of metaphors in education. The third section demonstrates the methodology of metaphor analysis used; the fourth presents and analyzes the metaphors; and the last discusses the findings and their influence on aspects of practice teaching.

\section{Metaphors in Education Research}

The Greek philosopher Aristotle defined the metaphor as "the application to one thing of the name belonging to another" (Aristotle, 1924). Metaphors are natural cognitive tools of the mind (Gidron \& Cohen-Or, 2007). They are more than rhetorical or linguistic techniques; they are at the heart of human thought and are used not only for simple communication but to give substance to understanding life (Lakoff, 1987; Lakoff \& Johnson, 1980; Torr \& Simpson, 2003, 1996; Turner, 1987; Wickman et al., 1999). A metaphor is a rich image made simple, so that one word or expression can be worth countless ones. The rich inner world of the individual can find authentic expression through the use of metaphors (Rabinowitz \& Kacen, 1995). Moreover, the focus of the metaphor lies in the way the individual conceptualizes one mental domain using the con- cepts of another (Lakoff, 1993). Metaphors therefore have added value, expressed in their power to throw new light on two concepts by interlacing them, and by joining entire domains through semantic concepts (Lakoff \& Cornelissen, 2004). Metaphors are consequently a fundamental tool for understanding the world of people (Wickman et al., 1999) and they reflect the cultural experiences of the individual (Ying, 2007).

Kupferberg (2005) suggests that development of the professsional selves of teacher-training students can be understood through dialogic studies, including analysis of metaphors. Accordingly, metaphors play an important role in the process of character building and teachers' search for self, stemming from the help they provide students and teachers during the learning process (Bullough \& Stokes, 1994). Consequently, the use of metaphors in teacher training reinforces what has been learned and increases the motivation to learn: students report that speaking and writing through metaphors helped develop a better picture of themselves as teachers (Hagstrom et al., 2000).

In teacher training, metaphors make it easier for students to understand themselves on the emotional and cognitive levels and provide them the opportunity to reflect on themselves, which is necessary for their cognitive development during training (Handy, 1998); it helps them understand long and complex explanations easily and concisely (Rasmussen, 2001); heightens their inner awareness of problems and contributes to developing coping tools, and motivates and reinforces their ability to understand reality and events around them in novel ways (Rasmussen, 2001; Siegelman, 1990). The metaphor also makes it easier for students to understand conflicting insights and emotions, create cognitive consonance between external stress stemming from reality and inner psychological stress, and balance between the ideal and real (Zilberman et al., 1995). It allows students to find a holistic definition for the complexity and dynamics of the process and paves the way for them to name the elements that comprise a certain situation without losing the whole picture of the process (Gidron \& Cohen-Or, 2007). Through metaphor, students convey the meaning of their statements and their values (Cornelissen, 2004). Those who used metaphors during the learning process developed the ability to think more creatively (Lawley \& Tompkins).

Teachers use metaphors to explain to students the meaning of learning. Each metaphor contributes to forming certain insights into the complexity of learning (Vakkayil, 2008). Using metaphors helps teachers cope with quiet or reticent students, examine how they understand the learning materials, follow how they integrate areas of study they manage independently and those they need help with, and understand how they teach (Lawley \& Tompkins, 2000; Rasmussen, 2001). Students describe one kind of experience in terms of another by way of metaphors in ways that reflect what they think about the original experience (Lakoff \& Johnson, 2000). Rasmussen (2001) used the metaphor "scaffolding" to describe the support students require from their teachers during the learning process to help them build their professional characters. In the end, metaphors influence the day-to-day functioning patterns of students and teachers alike (Growth \& Bergner, 2005). They ultimately provide the means to study and analyze teachers' and students' patterns of thought. They can strengthen or weaken learning opportunities (Bullogh \& Stock, 1994).

Apparently, speaking through metaphors is characteristic of teachers and students (Alger, 2009; Robinson, 2000). This may stem from the ability of the metaphor to bridge between differ- 
ent elements, including those that are distant from one another, and doing so, make the meaning clearer, which is at the very heart of teaching and learning. Consequently, understanding metaphors is an extremely helpful tool in research, particularly in the field of education. Alger (2009) found that metaphors are dynamic and change as perceptions change and individuals undergo professional development in the field of education. East, (2009) suggests that using metaphors as a self-study tool is a way for the teacher to step back from practice and uncover new meanings within him/herself. Robinson (2000) found that in daily conversation students use metaphors at least four times per minute. Bozik (2002) examined the level of coherence between courses for liberal education among first-year students, researchers. He found that the students demonstrated increased ability and expansion of their vocabulary of metaphors during the first year.

This paper analyzes and throws light on the students' perceptions of their student teaching experience as revealed by their metaphors, and draws a number of conclusions regarding the training process. The analysis of metaphors in this paper aims to reveal the experiences of students, their intra- and inter-personal worlds, how their selves were formed and how the students evince them.

\section{Methodology}

Data collection and analysis of this study is based on metaphor analysis. This method has a number of advantages: metaphors are tools for gathering information, finding common patterns, and comparing elements; for presenting the paradoxical and ironical; for connecting many cases to form one principle; and for presenting a whole through one of its parts (Miles \& Huberman, 1994).

The data collected is based on metaphoric stories students were requested to write towards the end of their first year of study, using metaphors to describe their student-teaching experience throughout the year. The research population was thirty-five female students in their first year of studies during the 2009 school year, studying in a retraining program towards a B.Ed. degree in early childhood education. Each of them was asked to place her story in the mailbox of the researchers, who later collected them. This is a multiple case study in which the story of each student is considered a case. The stories underwent a unique four-phase quantitative analysis (Jabareen, 2004, 2009; Ezzy, 2002; Huberman \& Miles, 1994; Rossman \& Rallis 1998): Phase one: Identifying and listing metaphors appearing in the students' stories, through careful analysis of each and every story. Phase two: Identifying regularities and repetitions in the metaphor themes identified during the first stage in all the stories. This analysis is meant to identify central recurrent categories in the data that describe clear patterns of the phenomenon under study. Phase three: Reduction in the number of metaphors by combining and joining related ones. Phase four: Final naming the final categories identified and consolidated. The model and the meanings of the studied phenomenon were derived from the final categories.

\section{Results}

By analyzing the stories of the students' experiences during their practicum, the study found that student teaching progresses on a timeline over three accumulative stages of the practicum: 1) prior to the beginning of practicum; 2) during the practicum; and 3) towards the end of practicum. The study identifies ten categories that describe these three stages, classified according to the content worlds of the metaphors. This section therefore presents these categories and their metaphors according to these three stages.

\section{Prior to the Beginning of the Practicum}

By analyzing the stories of the students' experiences during their practicum, the study found that student teaching progresses on a timeline over three accumulative stages of the practicum: 1) prior this section therefore presents these categories and their metaphors according to these three stages.

Emotional loads: The most prominent metaphoric descriptions describing positive emotions like happiness and excitement were "twinkling and flashing eyes”, "a smile was painted on her face”, "my heart laughed and danced”; describing feelings of relief from apprehension were "a mountain/boulder/ weight was lifted from my shoulders", and "the bee/baby gave a sigh of relief". In comparison, the most prominent metaphors describing negative emotions like fear of failure were "I prayed I'd overcome the obstacle" and "I closed my eyes so as not to see the depth of the pit"; those that expressed confusion and lack of clarity were "my thoughts collided with one another", "the sunlight was blocked and darkness/fog hid the way/path", "everything around me is twisted", and "I felt I was in gloomy winter weather".

Cognitive loads: The students used metaphoric descriptions rich in content and scope in order to describe their ideas and the information and skills they brought (or didn't bring) with them to the practicum. Seventy-two metaphors appear in their descriptions reflecting their thoughts and ability (or occasionally, lack of ability) to cope with their new situation. The prominent metaphoric descriptions illustrating awareness of difficulties, apprehension, and uncertainty were "I expected spikes/drilling/ nails on the path", "I knew it would be dark some of the way", and "I knew there would be animals on the road". Some of the metaphors show they felt they possess the required wisdom: "I equipped myself with common sense and past experience", "I studied the width and breadth of the space/the sea/outer space", and "I carried scales in order to weigh my steps". In contrast, at this point there is a relatively low incidence of metaphors indicating lack of skill, knowledge, and familiarity with teaching methods. The most numerous metaphors were "the treasure of the forefathers", "I didn't know how a road is paved”, and "I hadn't encountered that rule”.

\section{During the Practicum}

After beginning the practicum: The students used a variety of metaphoric descriptions to express the experience of entering the world of student teaching. Their descriptions can be divided into two metaphoric content worlds: rebirth and moving from place to place. The most of the students chose to describe the beginning of the practicum as moving from one place to a another (of course, according to the rules of metaphor), though they differed in both content and attributes: "flight in the sky", "diving into the water", and "entering a hive". Eleven students described the beginning of their practicum as rebirth or a new beginning, and used metaphoric descriptions such as "leaving the womb" and "growing in a flower garden". It is interesting to 
note that the content worlds used by the students to describe the beginning of the practicum required they possess special aptitudes and skills to survive in the climate and conditions prevalent in these same places/worlds.

The practicum experience as a process: The students conceptualized their field experience using two classes of metaphor: the first describes the practicum as a developmental process and the second as a process of birth. The students use a variety of concepts with which to describe their practicum as processes of development and birth. The most frequent were "flight," "growth," and "underwater diving."

The actual practice teaching experience: In accordance with their outlook and experiences, the students used three concepts to metaphorically describe the world of practice teaching-first, as a milestone event; second, as a space with boundaries; and third, as a space without boundaries. Many students chose metaphors that describe the content world of their practice teaching as a space with clear boundaries and its own rules, such as "sea," "garden," "hive," "kitchen,” and "large city.” Such boundaries offer the possibility of controlling the space through learning and acquiring skills. Another 15 students chose metaphoric descriptions for the content world of their practice teaching as a space without boundaries, such as "outer space," "life," "sky," "dream”. Control over such spaces can be only partial and only those familiar with their characteristics can acquire the skill necessary to survive them.

Sources of motivation: The students frequently used metaphors to describe what motivated them to meet the challenges of practice teaching. According to these descriptions, their motivations come from either intrinsic (generated by the self) or extrinsic (generated by the cooperating teacher or faculty supervisor) sources. As noted above, the first group of metaphors originated in the intrinsic motivations of the students. The students used a total of 183 concepts to describe how they faced the challenges they confronted in the world of practice teaching. Their frequency was high and they were extremely rich in content. Some of the more prominent metaphoric descriptions belonging to the first category were those regarding persistence (I held on with my bare teeth, I stood firm against the wind/ waves/quakes); patience and survival (I healed my pains), will to continue studies (I will continue to dig despite the melting heat of the sun, I will stand firm against the wind and fly in the sky/in nature/in the sea); actively surmounting difficulties for the sake of success (I stood once more on the diving board, I picked up the pieces and glued them together); and love of the profession (I was drawn to climb mountains/trees/peaks, I loved to dive/fly/collect).The second group expresses extrinsic motivation provided by the cooperating teachers and faculty supervisors in both the emotional and cognitive realms. Of the 98 expressions used, 75 belong to the emotional realm, expressed through various metaphors such as support (I was nurtured like a flower, I was held like a baby; I depended on love) and encouragement (propped up against the wind, praised my efforts to the sky, applause). In the cognitive realm, a variety of metaphors were also used, such as success stories (beautiful memories from the past, legends of champions) and help in lesson planning (the roads were outlined, the ways were shaped).

\section{Interface Agents: The Self, the Faculty Supervisor, and the Cooperating Teacher}

The students described how they interacted with the three in- terface agents in their practicum: the self, the faculty supervisor, and the cooperating teacher:

The self interface agent: The first interface agent, the self, was described by students by way of three content worlds of metaphoric expressions: the human, the animal, and the plant. Many students used to describe their perceptions of their selves as a young apprentice, which reflects reality more than any other metaphor. Others, described the self as a person who had undergone a milestone experience (bride, infant, woman who gave birth), as opposed to some others who described the self as a person in need of knowledge and encouragement (someone who need strengthening, young apprentice).

The faculty supervisor interface agent: The students used the same metaphoric content worlds (human, animal, and plant) as in the previous table to describe how they experienced their faculty supervisors. The results show that most participants chose descriptions referring to the world of humans to describe their faculty supervisor. Of these, 6 metaphors described a mother, doctor, or captain. These descriptions teach us that the students experienced the faculty supervisor, on one hand, as someone who cares for, supports, heals, and rescues; and on the other, as a professional, expert, and someone who commands (captain), possessing a comprehensive vision of the student teaching process.

The cooperating teacher interface agent: Descriptions of the cooperating teacher also use the three metaphoric content worlds seen in the previous interfaces: the human, the animal, and the plant-inanimate. Many participants chose descriptions that relate the cooperating teacher to the world of humans, and others, described her as a helper and caregiver, expressing their need for her assistance. Furthermore, the other descriptions, such as mother, farmer, and submarine commander, show the participants perceived that the cooperating teacher was supportive, caring, and a driving force. The table also shows that 10 students chose descriptions that tied the cooperating teacher to the animal world. These descriptions show that the students felt the cooperating teacher was proficient in her field, an active leader who expends considerable effort.

\section{Towards the End of the Practicum}

The students offered insights they arrived at during the year-long practicum. Table 1 lists these insights as reported by the students. The findings show that various insights over the timeline that are different in content and in context. Insights 1 and 2 belong to the stage before the practicum began; 3 - 9 were acquired during the practicum, and 10 - 12 were shaped at the end of the process.

\section{Discussion}

Analysis of the metaphoric stories in this study reveals that education students described student teaching as a varied process made up of three accumulated stages along three points on a timeline: prior, during, and towards the end of the practicum. The analysis of the metaphors used in the stories demonstrates the students' outlooks on their teaching experiences.

Prior to the start of the first phase of their student teaching experience, the students described their feelings and thoughts from two perspectives: emotional and cognitive. Since it is impossible to separate the emotional from the cognitive, which is comprised of professional knowledge and attitudes towards 
Table 1.

Distribution of the insights derived from the practicum.

\begin{tabular}{ll}
\hline \multicolumn{1}{c}{ Insights from the practicum } & \multicolumn{1}{c}{ Metaphors } \\
\hline $\begin{array}{l}\text { 1) It is a process of understanding } \\
\text { and inner awareness, of } \\
\text { understanding reality and the }\end{array}$ & $\begin{array}{l}\text { Encounter with the self (5), breaking } \\
\text { boulders (2); facing reality (2); } \\
\text { discovering treasure (2); understanding } \\
\text { difficulties, and realizing you } \\
\text { don’t know everything }\end{array}$ \\
$\begin{array}{ll}\text { the recipe (2); facing weakness (2); } \\
\text { mixing new paints (2) }\end{array}$ \\
$\begin{array}{ll}\text { 2) The process is long and requires } \\
\text { patience and coping with } \\
\text { obstacles }\end{array}$ & $\begin{array}{l}\text { Spreading wings against the wind (4); } \\
\text { chasing away the darkness (2); } \\
\text { absorbing the pain (1); standing up } \\
\text { straight to meet challenges (1) }\end{array}$
\end{tabular}

3) A process full of surprises, disappointment, and uncertainty

A path full of hiding places and ambushes (4); a very winding road (4); a path full of thorns and briars (4); a journey with no road signs (4)

Pleasure from flying/diving (4); enjoying riding the waves (4); searching for coral/stones/colors (4); uncover the roots (2) discover and learn

Pushing the trolley forward (5); to

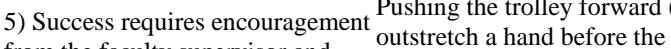
from the faculty supervisor and sailing/dive (4); to fuel the emotions coordinating teacher (4); stiffen the backbone (1)

6) Initiative is required from the student as well

Jumping/diving into the water (5); taking off into the sky (4); paving the way (3)

Meeting a flock of birds/a swarm of

7) Many players have roles in the process

bees/a school of fish (6); being familiar with the audience/the farmer/owner of the garden (4);

8) Success depends on asking for advice and sometimes for help

Dancing the tango (4); playing cards (2); arm-in-arm (2); walking

hand-in-hand (1)

9) Love of the profession is an indispensable element of success

10) This is a continual learning process

Falling in love with diving/flight/dance (3); enthusiasm for the journey (3); to desire the rich world (2)

To continue the journey (3); to set the wheel in motion (2); to dig in the ground (1)

11) The process involves changing attitudes, accepting criticism, and respecting the opinions of the other

12) The process is individual
Listening to the sounds of the musicians (3); to feel the inner voices (2); to sway with the wind (1)

To sink into the self (2); to swim/play music/climb alone (2); experience loneliness

the profession (Segal et al., 2009), the students saw the two as complementary, and accordingly referred to both. Descriptions of their emotional loads included negative emotions like fear of failure, tension, stress, and confusion; and positive emotions like happiness, excitement, calm, and satisfaction. Studies have shown that the emotional state of teacher trainees has not been widely studied (Segal et al., 2009). Yet, the findings of this study indicate that students come to the practicum with emotional loads that can be of help for them over time by motivateing and helping them integrate into the learning experiences related to their training. The cognitive load, according to the students' descriptions, included some skills they felt they possessed or did not possess at the very beginning of the practicum. The incidence of concepts describing having cognitive loads,

like awareness of difficulties; apprehension; and uncertainty, is high. On the other hand, the incidence of skills that they lack, mainly information, tools, and teaching skills and methods, is low as the process begins. Previous studies show that teachers in-training bring with them to the practicum professional, emotional, and communicative attitudes, and information relating to the teaching profession. This helps them integrate during their training and is a basis for development of identification with the profession and consolidation of a pedagogic orientation (Parkison, 2008b, 2009). A previous study found that before beginning practice teaching, tension and unpleasant thoughts and feelings were prevalent among trainees. They welcomed learning about practical didactic tools before the practicum in hopes of reducing the gap between theory and practice during their teaching experience (Smith \& Lev Ari, 2005).Studies show that both the emotional and cognitive loads, not yet focused and balanced before entering the practicum, become so during the process, after the students' exposure to theory and practice, which is the basis of developing practical wisdom (Lunenberg \& Korthagen, 2009).

The students considered their transition to student teachers significant and exciting, and described it (before and during) as a passage from one place to another one different in content and character. The metaphoric descriptions they used were "flying from land to sky", and "leaving the womb to begin life". They also described the practicum as a long, dynamic process (flight and growth); a milestone event (marriage); a space with boundaries (the sea); and a space without boundaries (outer space). It is evident from the content worlds used by the students to describe their debut into practice teaching that they believed they needed special capabilities and specific skills in order to face the initial and ongoing challenges of the practical experience. The preliminary period is characterized by stress among the students both because of the new challenges of the practicum and their academic studies. Studies show that although the students continue to study teaching during the practicum, they are afraid they are ill-prepared to enter the classroom and school. They still lack the ability to cope with new challenges and stress, as well as didactic and practical tools and tips for creating alternative activities and dealing with disciplinary problems (Lehavi, 2009; Segal et al., 2009; Smith \& Lev Ari, 2005).

The students recounted two types of motivation that helped them face challenges during student teaching. The first was intrinsic, its origin their inner strength and personalities. This finding concurs with that of Segal, Ezer, \& Gilat (2009); i.e., motivation to teach involves satisfaction with the decision to study teaching and commitment to joining the teaching profession in the future. These parameters are similar to those of the present study, that is, devotion to the objective, wanting to teach, and loving the profession. The second type of motivation, as described by the students, is extrinsic - it originates from encouragement received from the cooperating teacher and faculty supervisor. Developing motivation in trainees is an essential and integral part of training them (Mishali, 2001). Cooperating teachers and faculty supervisors understand their support must come through positive reinforcement, focusing guidance conferences on those areas that require improvement, and including words of approval in the dialogue (Dayan, 2000). Ultimately, motivation to teach is an important and central element in successful integration into the profession and satisfaction with it.

How did the students perceive the interface agents during the 
practicum: the self, the faculty supervisor, the cooperating teacher, and the pupils? The first three were described on the basis of two content worlds: the animate and the inanimate, or more specifically, the human, animal, and plant/inanimate worlds. It should be noted that very few metaphors came from the inanimate, and those that did were naturally from the computer (e.g., change the disc) and automotive (e.g., I lost the brakes) spheres, but nature and people were dominant, a potential direction for future research. This could be explained by the fact that the participants are close to nature, to children's literature, and are familiar with reading materials that tend to use metaphors from nature and not from the inanimate. Regarding the self, students seemed to perceive themselves as weak and in need of help, encouragement, and support. A reading of the literature shows that the process of professional training for the service professions is long, difficult, and involves the painful meeting of the student with his/her emotions and weaknesses. The role of the supervising instructor, according to the literature, is to observe the student and diagnose problems, using behavioral design techniques to provide effective solutions (Dayan, 2000); to provide socio-psychological support; to promote a professional attitude; and to make use of essential training skills to encourage appropriate teaching assignments-both on the classroom and socio-institutional levels; and promote evaluation, feedback, and reflection (Emmanuel, 2005). The present study reveals that the supervising instructor was perceived as a role model and leader, and indeed, as an overseer and pilot. Finally, descriptions of the cooperating teacher reflected visions of her as a mother figure, teacher, and mentor, someone with knowledge and experience. Her role is to open the classroom to the students; integrate them into the work culture; help them prepare lessons; follow their work; analyze their activities together; and act as a model for imitation and identification.

It is noteworthy that none of the participants in the present study described their pupils as an interface agent. This may be explained by the students being so involved in their new challenges and the stress they were under that only further along the line will they be open to learning about the pupils who will be in their classes. Professional literature is rife with the term "reality shock" to describe the transition to field work, which is often thought of as dramatic and traumatic (Adams, 1982). The shock experienced by beginning teachers is not merely for the short term, but marks the start of internalizing a complex reality that demands from its participants continuous learning and familiarity with new elements, especially during the initial stages of student teaching (Lzovsky \& Schrift, 1992). Not referring to their pupils can also be attributed to the cultural context reflected in the teaching models the participants in the study were exposed to and internalized as students, which are a significant influence on their personal and professional development (Reichenberg \& Sagi, 2003); and by the nature of Arab society, in which school children are of marginal importance and teachers are mainly concerned with meeting the expectations of parents and other teachers (Dwairy, 2001). This may have influenced the participants, resulting in them not focusing on their pupils.

The findings present a variety of insights the students had gained by the end of the practicum, which can be referred to as practical wisdom, since they reflect the sensitivity and awareness of the students to teaching, to the conditions they find themselves in, and their methods of coping. Insights such as "a process of understanding and internal awareness, of understand- ing reality and its difficulties, and realization that they don't know everything” point to growth and professional maturity. Practical wisdom reflects a high level of professional growth that occurs throughout the period in which trainees and beginning teachings acquire experience in day-to-day teaching (Lunenberg \& Korthagen, 2009). It is acquired as the trainees organize their knowledge by developing an understanding of the relationship between experience and theory (Korthagen \& Lagerwerf, 2001).

The findings of the present study teach us much about the participants in the student teaching process. This information can be used to improve the process vis-à-vis the needs of the trainees. In light of this, one way to act based on such findings is to become more familiar with the feelings, perceptions, and personal traits of the trainees before the practicum begins. This can be done with the help of various tools, or combination of tools, such as questionnaires, personal interviews, card games, and goal-oriented compositions and analysis of the resulting texts and metaphors, in accordance to the situation and at the discretion of the supervising instructor. Having such information about the trainees before they enter the practicum can help them deal with such issues as stress reduction.

It is also important to familiarize the students with all the interface agents in the practicum and their roles: the supervising instructor, and cooperating teacher, the pupils, and the students themselves. Advance familiarity is likely to make the work of the cooperating teacher and supervising instructor more effective from the beginning (after the students have begun practice teaching until the end) by allowing them to adjust the training content to match circumstances and the development and needs of the trainees, while emphasizing the relevant attributes required to mold their professional and person identities.

Regarding the pupils, evaluators of student teachers should be aware that the start of the practicum is not always the proper time for the trainee to focus on the pupils in his/her class; nor is it the time to learn about formative assessment and evaluation, about openness and criticism. These topics become relevant to the trainees only later, after they are finished attending to their own issues, have survived their experience, and acquired selfconfidence. It is important to note that the supervising instructor and cooperating teacher (partners-evaluators) are an essential source of motivation to the students and, according to them, the extrinsic source of their motivation, on top of the dynamics and challenges that form the students' intrinsic motivation.

\section{REFERENCES}

Adams, R. D. (1982). A look at changes in teacher perceptions and behavior across time. Journal of Teacher Education, 33, 40-43. doi: $10.1177 / 002248718203300410$

Alger, C. (2009). Secondary teachers' conceptual metaphors of teaching and learning: Changes over the career span. Teaching and Teacher. Education, 25, 743-751. doi:10.1016/j.tate.2008.10.004

Awad, Y., Zoabi, Kh., \& Khalil., M. (2009). Pre training mapping among students in the preschool education program. Bamichlala: Research, Essays, Literary Works. 211-237.

Beyer, L. (1984). Field experience, ideology, and the development of critical reflectivity. Journal of Teacher Education, 35, 36-41. doi:10.1177/002248718403500308

Bozik, M. (2002). The college student as learner: Insight gained through metaphor analysis-Statistical data included. College Student Journal. URL (last checked 7 July 2009). http://findarticles.com. 
Bujold, C. (2004). Constructing career through narrative. Journal of Vocational Behaviour, 64, 470-484. doi:10.1016/j.jvb.2003.12.010

Bullough, R. V., \& Stokes, D. K. (1994). Analyzing personal teaching metaphors in pre-service teacher education as a means for encourageing professional development. American Educational Research Journal, 31, 197-224.

Cimrman, H. (2000). The kindergarten teacher trainer and the art of training. Hed Hagan, Booklet 4.

Cornelissen, J. (2004). What are we playing at? Theatre, organization, and use of metaphor. Organization Studies, 25, 705-726. doi: $10.1177 / 0170840604042411$

Dayan, Y. (2000). Observation-What does the pedagogical instructor do during her stay in the kindergarten? Hed Hagan, 4, 48-61.

Dwairy, M. (2009). Culture-analysis and metaphor therapy with ArabMuslim clients. Journal of Clinical Psychology, 65, 199-209. doi:10.1002/jclp.20568

Dwairy, M. (2001). Foundations of psychological dynamic personality theory of collective people. Clinical Psychology Review, 22, 343360. doi:10.1016/S0272-7358(01)00100-3

East, K. (2009). Using metaphors to uncover the selves in my practice. Studying Teacher Education, 5, 21-31. doi:10.1080/17425960902830377

Emmanuel, D. (2005). Perceptions of the role of faculty supervisor from three points of view. In M. Silberstein, \& R. Reichenberg (Eds.), Renewed consideration of the curriculum for training faculty supervisors (pp. 62-106). Tel Aviv: Mofet Institute.

Evans, R. (2007). Existing practice is not the template. Educational Researcher, 3, 560-563.

Ezzy, D. (2002). Qualitative analysis, practice and innovation. London: Routledge.

Fresko, B. (2009). The study of professional development narratives: That's the whole story! Al Hagova, 8, 21-23.

Gidron, A., \& Cohen-Or, D. (2007). Two languages one tongue: The working metaphor. Imaginative Education: Provoking Excellence across the Curriculum. Imaginative Education Research Group.

Groth, R. E., \& Bergner, J. A. (2005). Pre-service elementary school teachers metaphors for the concept of statistical sample. Statistics Education Research Journal, 4, 27-42.

Handy, C. (1998). A proper education. Change, 30, 13-19. doi:10.1080/00091389809602637

Hagstrom, D., Hubbard, R., Hurtig, C., \& Mortola, P. (2000). Teaching is like...? Educational Leadership, 57, 24-27.

Hale, A., Snow-Gerono, J., \& Morales, F. (2008). Transformative education for culturally diverse learners through narrative and ethnography. Teaching and Teacher Education, 24, 1413-1425. doi:10.1016/j.tate.2007.11.013

Hoy, W. K., \& Woolfolk, A. E. (1990). Socialization of student teacher. American Educational Research Journal, 27, 279-300.

Huberman, A. M., \& Miles, M. B. (1994). Data management and analysis methods. In N. K. Denzin, \& Y. S. Lincoln (Eds.), Handbook of Qualitative Research (pp. 428-444). Thousand Oaks, CA: Sage Publications.

Jabareen, Y. (2009). Building conceptual framework: Philosophy, definitions and procedure. International Journal of Qualitative Methods, 8, 49-62.

Jabareen, Y. (2004). A knowledge map for describing variegated and conflict domains of sustainable development. Journal of Environmental Planning and Management, 47, 623-642.

doi:10.1080/0964056042000243267

Kagan, M. D. (1992). Professional growth among preservice and beginning teachers. Review of Educational Research, 62, 129-169.

Koro-Ljungberg, M. (2001). Naming the multiple: Segments of scientific giftedness. Research Report 232, Helsinki: University of Helsinki,. Yliopistopaino.

Korthagen, F. A. J., \& Lagerwerf, B. (2001). Teachers' professional learning: How does it work? In F. A. J. Korthagen et al. (Eds.), Linking theory and practice: Thepedagogy of realistic teacher edu- cation (pp. 175-206). Mahwah, NJ: Lawrence Erlbaum.

Lakoff, G. (1993). The contemporary theory of metaphor. In A. Ortony (Ed.), Metaphor and thought (2nd ed., pp. 202-251). Cambridge: Cambridge University Press.

Lakoff, G. (1987). Women, fire, and dangerous things: What categories reveal aboutthe mind. Chicago, IL: University of Chicago Press.

Lawley, J., \& Tompkins, P. (2000). Metaphors in mind: Transformation throughsymbolic modelling. London: Developing Company Press.

Lunenberg, M., \& Korthagen, F. (2009). Experience, theory and practical wisdom in teaching and teacher education. Teachers and Teaching: Theory into Practice, 15, 225-240.

Miles, M. B., \& Huberman, A. M. (1994). Qualitative data analysis. (2nd ed.). Newbury Park, CA: Sage.

Parkison, T. P. (2009). Field-based preservice teacher research: Facilitating reflective professional practice. Teaching and Teacher Education, 25, 798-804. doi:10.1016/j.tate.2008.11.017

Parkison, T. P. (2008a). Field placement treatments: A comparative study. The Teacher Educator, 43, 29-45.

doi:10.1080/08878730701728879

Parkison, T. P. (2008b). Space for performing teacher identity through Kafka and Hegel. Teachers and Teaching: Theory and Practice, 14, 51-60.

Rasmussen, J. (2001). The importance of communication in teaching: A systems theory approach to the scaffolding metaphor. Curriculum Studies, 33, 569-582.

Renee, D. K., \& Bruno, D. J. (2000). When help us helpful: Parent and helper perspectives. ERIC Journal. Number EJ605021.

Richards I. (1936). The philosophy of rhetoric. Oxford: Oxford University Press.

Robinson, S. M. (1999). Meeting the needs of students who are gifted and have learning disabilities. Intervention in School and Clinic, 34, 195-204. doi:10.1177/105345129903400401

Rodgers, A., \& Keil, V. (2007). Restructuring a traditional student teacher supervision model: Fostering enhanced professional development and mentoring within a PDS context. Teaching and Teacher Education, 23, 63-80. doi:10.1016/j.tate.2006.04.012

Ross, W. (Ed.) (1924). The works of Aristotle in poetics. Oxford: Oxford University Press.

Rossman, G. B., \& Rallis S. F. (1998). Learning in the field: An introduction to qualitative research. Thousand Oaks, CA: Sage Publications.

Shapiro, B. L. (1991). A collaborative approach to help novice science teachers. Alberta Journal of Educational Research, 37, 119-132.

Siegelman, E. (1990). Metaphor meaning in psychotherapy. New York, NY: The Guilford Press.

Torr, J., \&, Simpson, A. (2003). The emergence of grammatical metaphora: Literacyoriented expressions in the everyday speech of young children. In A. M. Vandenbergen, M. Taverniers, \& L. Ravelli, (Eds.), Grammatical metaphor (pp. 169-183). Amsterdam: John Benjamins.

Vakkayil, J (2008). Learning and organizations: Towards cross-metaphor conversations. Academic Journal Learning Inquiry, 2, 13-27. doi:10.1007/s11519-008-0025-5

Ville, I., \& Khlat, M. (2007). Meaning and coherence of self and health: An approach based on narrative of life events. Social Science \& Medicine, 64, 1001-1014. doi:10.1016/j.socscimed.2006.10.014

White, M. (2006). Working with people who are suffering the conesquences of multiple trauma: A narrative perspective. In D. Denborough (Ed.), Trauma: Narrative responses to traumatic experiences (pp. 25-85). Adelaide: Dulwich Center Publication.

Wickman, S. A., Daniels, M. H., White, L. J., \& Fesmire, S. A. (1999). A "primer" in conceptual metaphor for counselors. Journal of Counseling \& Development, 77, 389-394. doi:10.1002/j.1556-6676.1999.tb02464.x

Ying, S. H. (2008). The role of culture in metaphor. US-China Foreign Language, 5, 74-81. 